\title{
EL SITIO ARQUEOLÓGICO MYREN 2, TIERRA DEL FUEGO, CHILE ${ }^{1}$
}

\author{
ALFREDO PRIETO*, ELISA CALÁS**, FLAVIA MORELLO"Y JIMENA TORRES**
}

\begin{abstract}
RESUMEN
Se da cuenta del contexto de un sitio arqueológico de especiales características, por hallarse inmerso en un antiguo turbal y por su datación de ca. 4.000 años AP. Los análisis líticos y arqueofaunísticos del sitio Myren 2 apoyan la idea de que se trata de un sitio de difícil adscripción funcional, pero muy interesante por la información que entrega y su carácter ejemplar para la Tierra del Fuego.
\end{abstract}

PALABRAS CLAVES: Arqueología, turbal, cazadores-recolectores, Tierra del Fuego.

\section{MYREN 2 ARCHAEOLOGICAL SITE, TIERRA DEL FUEGO, CHILE}

\begin{abstract}
The context of an archaeological site with special characteristics, because it is immerse in a peat bog and for its dated age of ca. $4.000 \mathrm{BP}$, is described. The lithic and archaeofaunistic analysis of Myren 2 site support the idea that it is hard to ascribe functionally, thought it contains interesting information and an outstanding character for Tierra del Fuego.
\end{abstract}

KEY WORDS: Archaeology, peat bog, hunter-gatherers, Tierra del Fuego.

\section{INTRODUCCIÓN}

La Estancia Myren se ubica en la isla grande de Tierra del Fuego, a poco más de una decena de kilómetros al norte de la costa de bahía Inútil, en un sector denominado caleta Puerto Nuevo. Entre septiembre y octubre de 2006 se llevaron a cabo labores de excavación de sondeo y prospecciones en el sitio Myren 2 y sus alrededores ${ }^{2}$ (Fig. 1). El sitio había sido encontrado y previamente sondeado en

1 El estudio preliminar del sitio Myren 2 comenzó con su redescubrimiento en 1999 en el marco del proyecto FONDECYT 1960027, dirigido por Mauricio Massone, y actualmente se ha ampliado y profundizado su estudio por interés de los proyectos FONDECYT 1060020 y 1070709.

* Centro de Estudios del Hombre Austral, Instituto de la Patagonia, Universidad de Magallanes y Centro de Estudios del Cuaternario (CEQUA). Av. Bulnes 01890, Punta Arenas, Chile. alfredo.prieto@umag.cl, flavia.morello@umag.cl.

* Licenciada en Antropología mención Arqueología. Depto. Antropología, Fac. Ciencias Sociales, Universidad de Chile. elisa.calas@gmail.com, jimenatorres77@gmail.com.

2 La estancia Myren tiene 3250 hectáreas, su eje mayor está orientado norte-sur, es atravesada por el cañadón Portales en su parte media y por el río Centenario en su límite sur. 
1999, durante el proyecto FONDECYT 1960027 dirigido por Mauricio Massone. En aquella oportunidad sólo se trató del reavivado de los perfiles del pozo de agua del casco de la estancia, propiedad de la familia Krussell. El pozo de agua se encuentra en el lugar donde antiguamente se ubicaba una vertiente natural ${ }^{3}$. Efectivamente, el dueño de la estancia comentó que habían aparecido huesos al habilitarse este pozo, por lo cual se decidió revisar, aunque someramente, este lugar, previa autorización del propietario, quien, además secó temporalmente el pozo con una motobomba para poder trabajar en él.

Entonces, durante dos días, se revisaron y colectaron los huesos de la pila de escombros del pozo y se realizó un pequeño sondeo, reavivando los perfiles en la pared oeste, con vistas a tener un control estratigráfico mayor. Esta unidad fue denominada simplemente "Pozo" en 1999.

Los resultados preliminares obtenidos, indicaban que se trataba de un extraño caso de depositación de restos arqueológicos en una turbera (acumulación de restos orgánicos de lo que parecía ser Carex sp.) Un primer fechado radiocarbónico sobre hueso de guanaco de dicho sondeo arrojó una edad de 3.910 \pm 70 años AP (Beta 128092 - Massone et al. 1999). Myren 2 presentaba así, uno de los fechados más antiguos del Holoceno medio-tardío del norte de Tierra del Fuego.

Lo que esta excavación mostró fue que había existido una ocupación humana en el sitio con especiales características. Se habían desechado allí restos óseos con clara evidencia de huellas de corte y fracturas, además de restos sin huellas de actividad humana. Los restos líticos no fueron analizados entonces, pero se trataba de un conjunto de importancia dado que algunos ítems como bolas pequeñas y/o raederas podían ofrecer una imagen inicial sobre lo que se estaba produciendo desde finales del Holoceno medio, en adelante, en la parte centro norte de la isla Grande de Tierra del Fuego.

3 Harold Krussell fue el miembro de la familia que se ocupó de la instalación del casco de la nueva estancia. Cuando arribó al lugar del futuro emplazamiento, la vertiente que daría origen al pozo (Myren 2) ya existía. Poseía buen caudal y garantizaba agua todo el año, no así los chorrillos cercanos. La vertiente determinó el emplazamiento del pozo de agua.

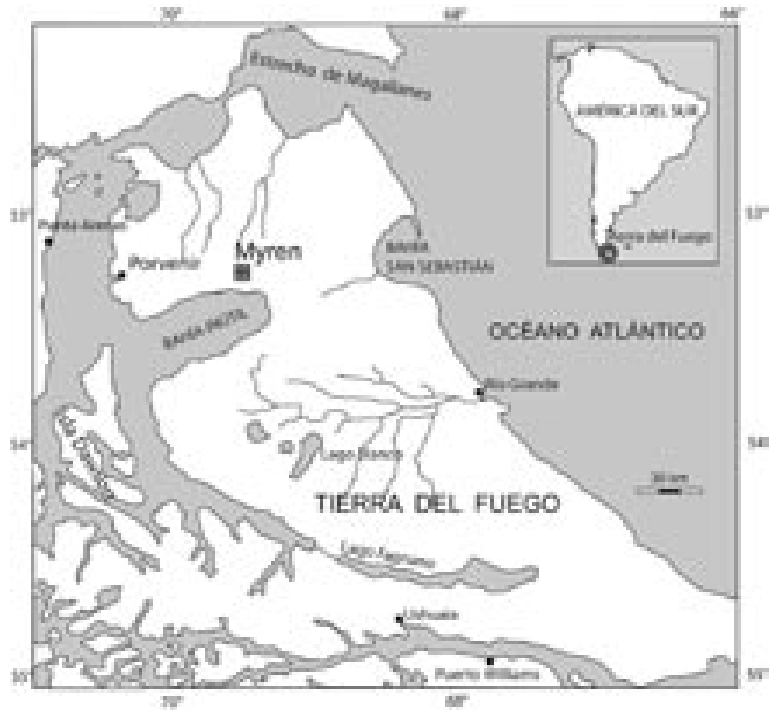

Fig. 1 Localización del sitio Myren 2, Tierra del Fuego.

El sitio era estratigráficamente llamativo, además, por la acumulación de los materiales arqueológicos en la base de la turba, casi apoyando sobre una capa de arcilla. Esto sugería que los restos pudieron infiltrarse por la capa de turba, hasta estabilizarse en la base de la misma o, que la acumulación de ellos se produjo cuando la turba recién comenzaba a formarse.

Es por ello que se decidió evaluar el potencial de este sitio en el marco del proyecto FONDECYT 1060020 y, en el año 2006, un equipo conformado por Alfredo Prieto, Elisa Calás, Gabriel Bahamonde y Pedro Cárdenas, realizó nuevos sondeos en el lugar.

\section{LAS EXCAVACIONES DE SONDEO}

La primera actividad a desarrollar consistió en la delimitación, a través de barrenados ${ }^{4}$, del sitio y la turbera en los alrededores del viejo pozo de agua. Contábamos con la información anterior en cuanto a que el sitio se componía de un abigarrado lecho de huesos de guanaco (Lama guanicoe). Buscando dar con este lente, se barrenó cada $1 \mathrm{~m}$, llegando hasta $3 \mathrm{~m}$ del pozo y a una profundidad máxima de 2,15 $\mathrm{m}$. La turba se restringía a los alrededores inmediatos del pozo, concentrando su mayor profundidad hacia la pared del pozo de agua que actualmente

4 Se utilizó un cabezal de barreno de $10 \mathrm{~cm}$ de diámetro. 


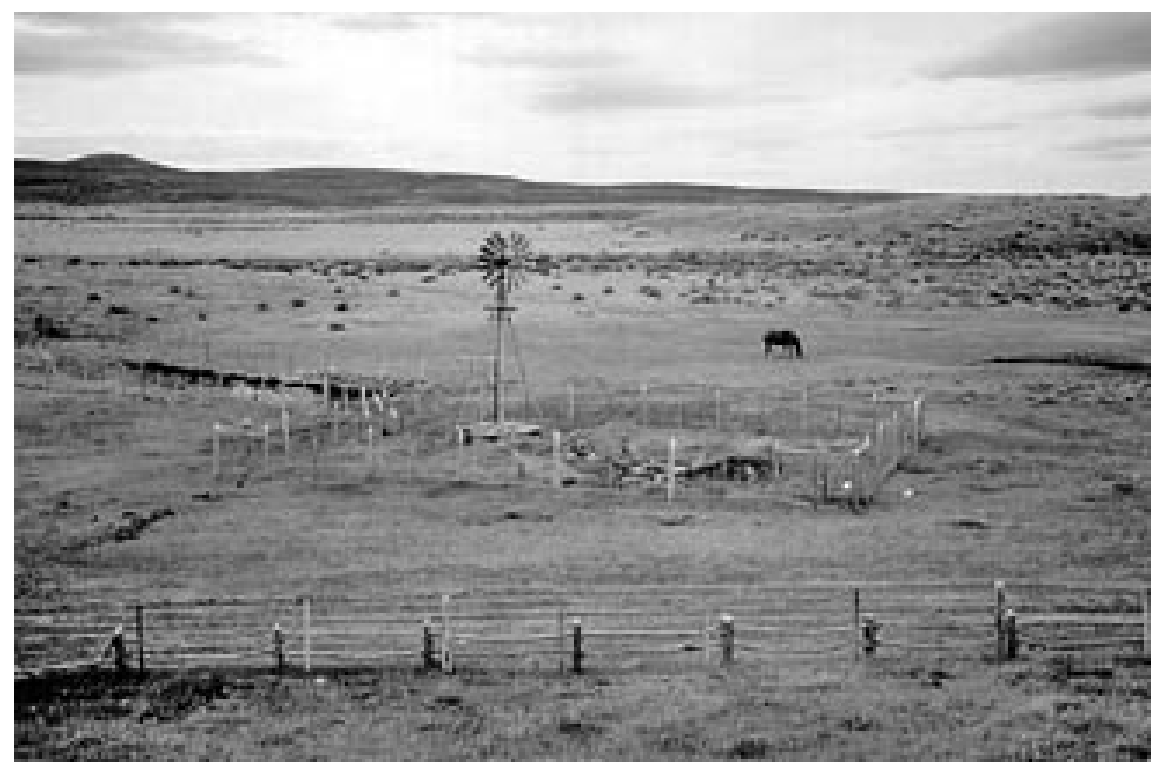

Fig. 2. Vista del emplazamiento del pozo de agua y del sitio arqueológico Myren 2.

abastece el casco de la estancia Myren (Fig. 2 y 3). La composición del suelo, aunque variable en profundidad, era siempre la misma, capa vegetal, turba, arcilla y luego una capa de guijarros. Los sondeos con barreno permitieron delimitar el lente con huesos de guanaco, extendiéndose sólo a 50 $\mathrm{cm}$ de distancia de la pared sur del pozo de agua, a 1 metro de profundidad, y a $50 \mathrm{~cm}$ de distancia al oeste, también a la misma profundidad. Sobre la pared sur yacía la escombrera del pozo de agua, se decidió excavar allí por haberse detectado una mayor concentración de restos óseos en los muestreos con barreno y en los perfiles del pozo una vez secado con motobomba.

Se planteó una cuadrícula paralela al viejo pozo, de $2 \times 1 \mathrm{~m}$, orientada su eje mayor en el sentido este-oeste. Las cuadrículas de $1 \mathrm{~m}^{2}$ se denominaron $1 \mathrm{~A}$ y $1 \mathrm{~B}$ (Fig. 3). En la pared norte

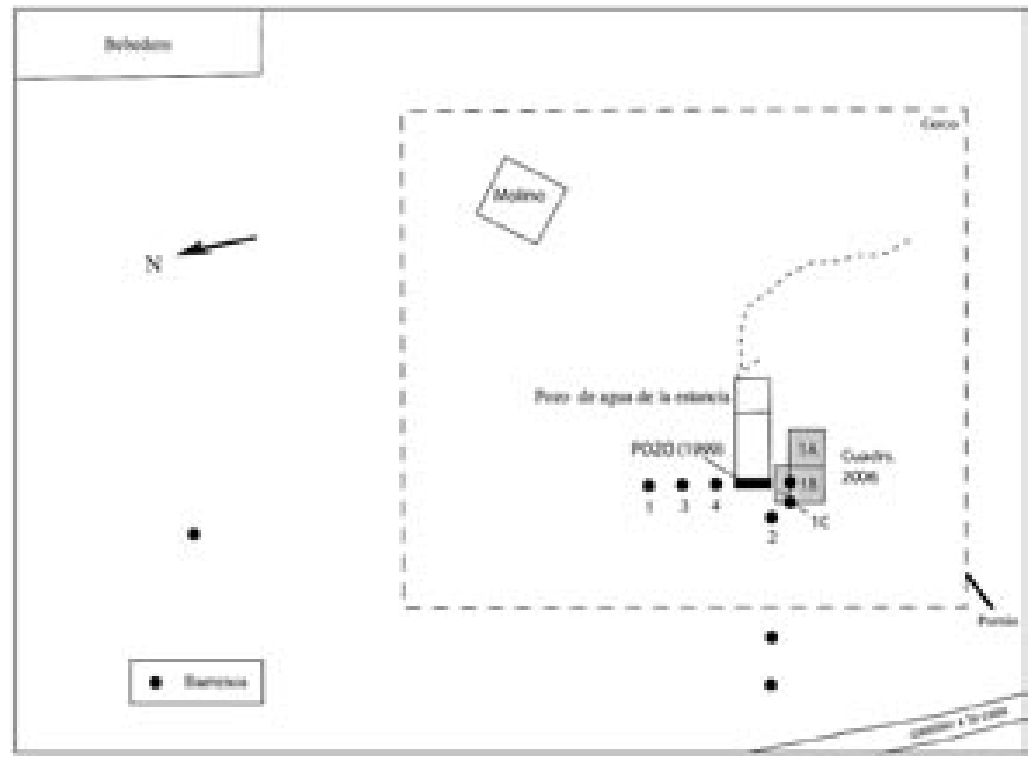

Fig. 3. Dibujo de planta del emplazamiento del sitio Myren 2 y el pozo de agua. 
la escombrera alcanzaba casi $60 \mathrm{~cm}$ de potencia, para dar paso a unos $45 \mathrm{~cm}$ de turba y luego arcillas (gris y azulina) hasta los $2 \mathrm{~m}$ en que aparecieron los guijarros. Esta secuencia estratigráfica se visualizó en un sondeo restringido a la cuadrícula $1 \mathrm{~B}$, dado que en la excavación de la turba superior no aparecieron huesos y sólo material lítico a los $85 \mathrm{~cm}$, en el contacto turba-arcilla (Fig. 4).

Los huesos aparecían hacia los 1,50-1,60 m en el pozo de agua, de modo que se avanzó hasta el nivel basal de la turba a lo largo de ambas cuadrículas (1A y $1 \mathrm{~B})$ sin hallarse el lecho de huesos que se apreciaban en el perfil del pozo, y registrándose solamente 5 artefactos líticos.

Por ello, se decidió avanzar la excavación 50 $\mathrm{cm}$ más hacia el pozo de agua, en la pared de la cuadrícula $1 \mathrm{~B}$, nueva unidad que se denominó $1 \mathrm{C}$. Existían dos elementos que debíamos tener en cuenta en esta excavación: se llenaba constantemente de agua y no debíamos contaminar el vecino pozo de agua de la estancia. Avanzamos hasta casi tocar la pared del pozo de agua, sin tocarlo de hecho (Fig. 3, Cuadrícula 1C).

De todos modos, dada la ausencia del lecho de huesos en las cuadrículas $1 \mathrm{~A}$ y $1 \mathrm{~B}$, todo hacía suponer que los huesos se hallaban confinados a las inmediaciones del pozo de agua y no se extendían más allá. Como señalamos, los artefactos líticos de las cuadrículas $1 \mathrm{~A}$ y $1 \mathrm{~B}$ comenzaron a aparecer hacia los -85 y $-110 \mathrm{~cm}$. Se trataba de dos raederas y tres piezas denticuladas sobre lascas - todos los instrumentos formatizados del sitio, es decir, 5 raederas (Fig. 13 y 14).

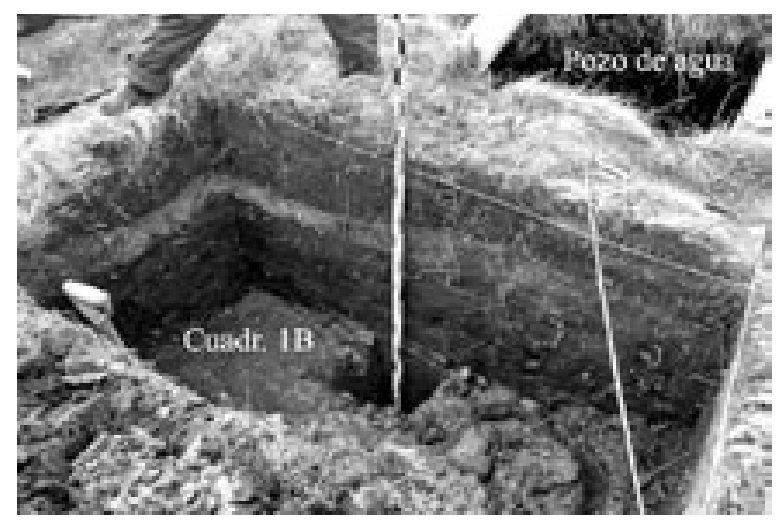

Fig. 4. Perfil Norte de 1A y 1B (2006) y el pozo de agua de la estancia.
La excavación, entonces, avanzó hacia la cuadrícula 1C. Este sondeo se delimitó en 1 x 0,40 $m$ hacia la pared del pozo de agua, y luego se redujo a una porción de $60 \times 40 \mathrm{~cm}$, dado que se abrió una vía de desagüe hacia el pozo de agua.

El sondeo en $1 \mathrm{C}$ puso finalmente al descubierto el lecho de huesos esperados, a los $-137 \mathrm{~cm}$, mostrando nuevamente una gran cantidad de restos óseos hacia la pared norte (Fig. 5). Comenzaron a aflorar cráneos y huesos largos, en posición horizontal, casi sobre la arcilla. Se identificaron al menos 5 guanacos por los axis en $1 \mathrm{~m}$ x $40 \mathrm{~cm}$. La excavación culminó a 1,50 m restringida a 60 × 40 $\mathrm{cm}$, dado que se abrían grietas hacia el pozo.

Se tomaron muestras de hueso y turba para fechar, se realizaron dibujos de planta y levantaron 81 restos óseos que incluyen casi exclusivamente guanacos (Fig. 6 y 7), aunque hay unos pocos restos de roedores, cánidos y líticos, entre otros materiales. Esta muestra no arrojó evidencia alguna de fauna introducida como lo ocurrido con anterioridad en la escombrera.

\section{FECHADOS RADIOCARBÓNICOS}

Las excavaciones de sondeo realizadas en el año 2006 apoyaban la idea de un lente de huesos de guanaco y materiales líticos que se ubicaban en la base de la capa de turba pero detenidos justo sobre la de arcilla (Fig. 6), lo que había sugerido anteriormente la reptación de materiales desde la superficie por medio de la turba -movimiento postdepositacional que sólo se detenía contra la compacta capa de arcilla. Esto, junto a la presencia

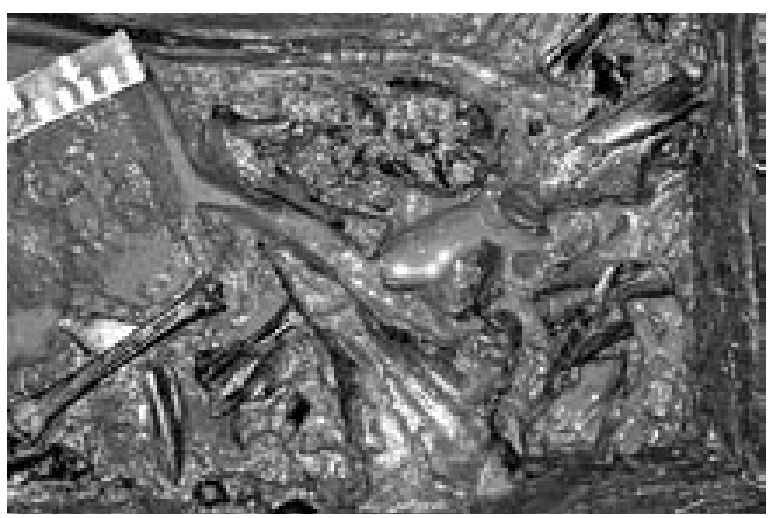

Fig. 5. Vista del lecho de huesos en la esquina NO de la cuadrícula $1 \mathrm{C}$. 


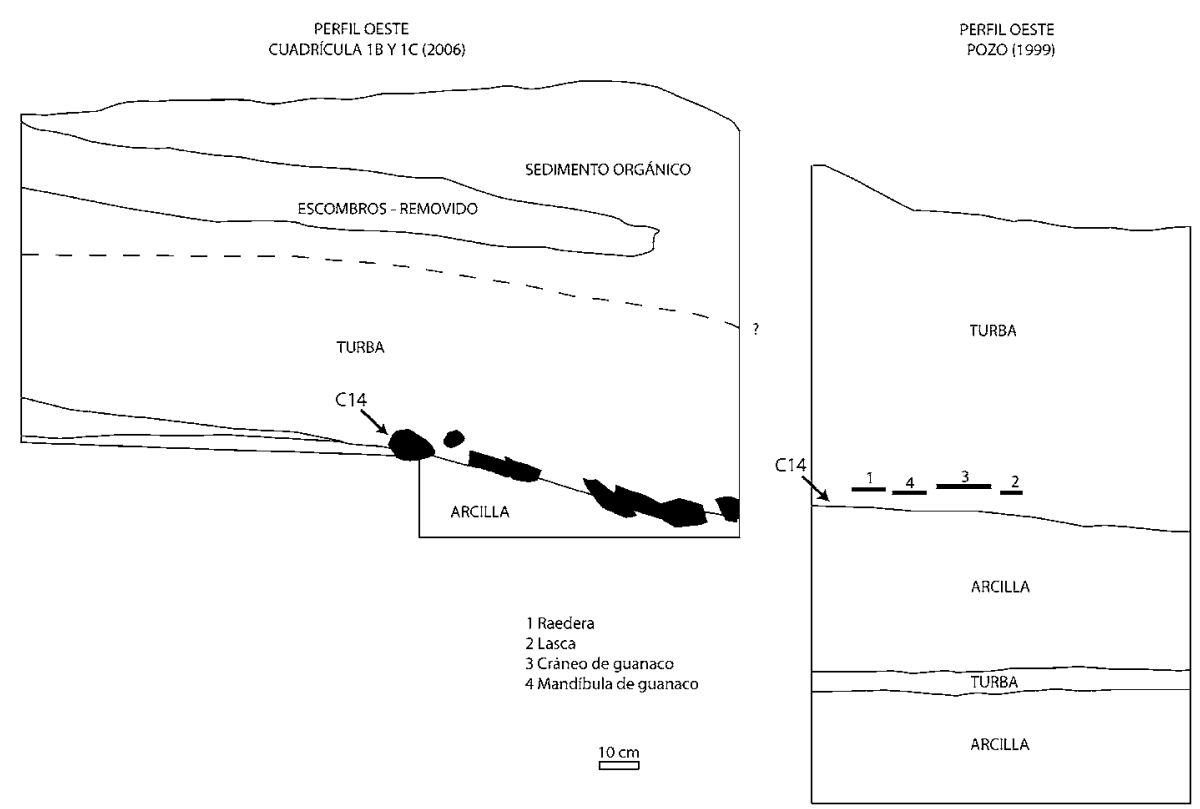

Fig. 6. Perfiles Oeste de los sondeos realizados en 1999 y 2006. Notar en negro la disposición de los restos óseos y la posición de dos de los huesos de guanaco fechados por C14.

tanto de huesos con claras huellas culturales como otros sin evidencia de acción antrópica, permitía suponer que el contexto cultural descrito como un único evento de depositación podría estar reflejando un palimpsesto de larga data. Es por esto que se decidió fechar otros dos huesos de guanaco, uno con huellas de corte y otro sin marcas culturales.

Los resultados fueron asombrosos, pues apoyaron la contemporaneidad del conjunto de huesos de guanaco y de los materiales líticos, por asociación. A la fecha existente de $3.910 \pm 70$ años $\mathrm{AP}$, los nuevos resultados agregaron $4.020 \pm 35^{5}$ (Ua-33943) y $3.820 \pm 35^{6}$ (Ua-33944) años AP.

\section{EL CONJUNTO ARQUEOFAUNÍSTICO}

Se registraron un total de 536 especimenes provenientes de ambas excavaciones de sondeo (1999 y 2006). El 92,4\% $(n=495)$ pudieron ser identificados anatómica y taxonómicamente con distintos niveles de especificidad. El resto (7,6\%) corresponde a fragmentos de huesos largos, fragmentos de huesos planos y tejido esponjoso, y pequeños fragmentos no identificados.

5 Vértebra cervical de guanaco sin huellas culturales.

6 Tarsal IV de guanaco con marcadas huellas de corte laterales.
En general, el conjunto se encuentra en buenas condiciones de conservación. En éste la meteorización es muy baja, lo que indica un rápido entierro de los restos. Esto seguramente incide en la baja presencia de huellas causadas por agentes naturales: huellas de roedor $(13,6 \%)$, huellas de carnívoros $(10,4 \%)$ y huellas de raíces $(12,7 \%)$. Un aspecto destacable del conjunto es la coloración negruzca y el pulimento por abrasión que presentan la mayoría de los restos óseos, seguramente por las características del sedimento en el que se depositaron los mismos (Fig. 5).

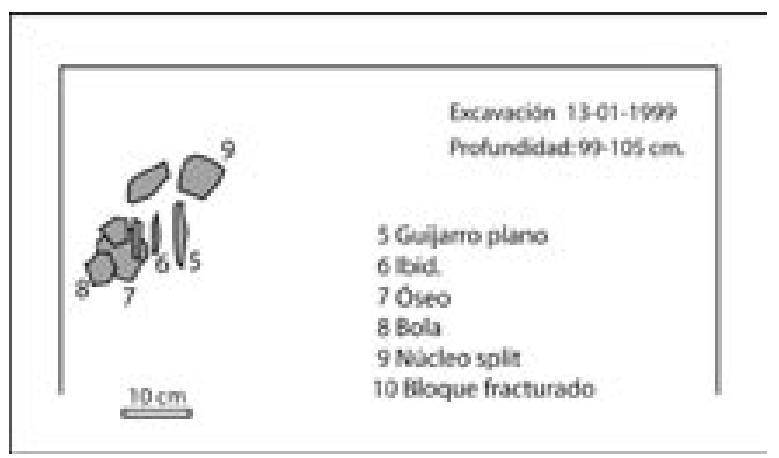

Fig. 7. Dibujo de planta de una de las concentraciones de material lítico de la unidad Pozo de 1999. 
El conjunto se encuentra compuesto principalmente por guanaco (Lama guanicoe) (77,6\%), seguido por oveja (Ovis aries) (1,9\%), zorro colorado (Pseudalopex culpaeus) (1,5\%), vaca (Bos taurus) $(1,1 \%)$ y coruro (Ctenomys magellanicus) $(0,4 \%)$. Además, un 9,9\% fue adscrito a la categoría de mamífero indeterminado (Tabla 1). La mayor parte de los huesos de vaca y oveja provienen de escombros sin procedencia estratigráfica recuperados en los trabajos realizados en 1999 y un porcentaje menor corresponden a restos de la excavación del $2006^{7}$.

A partir del MNE obtenido para el conjunto de guanacos se observa que un 59\% corresponde a individuos adultos y un $41 \%$ a individuos jóvenes, de estos últimos un 11,2\% corresponde a individuos neonatos. Esto nos permite determinar que los guanacos habrían sido cazados en verano (Raedeke 1979). Además, se identificaron al menos 9 individuos (Tabla 1), de los cuales se determinó que 3 son machos ( 2 adultos y 1 juvenil) y 2 son hembras adultas.

No obstante estos restos intrusivos no están asociados al leente basal de huesos de guanaco, sino que se encontraron en un sector superior de la capa de la turba.
Tabla 1. Composición taxonómica de la colección arqueofaunística.

\begin{tabular}{|l|c|c|c|}
\hline \multicolumn{1}{|c|}{ Taxa } & NISP & MNE & MNI \\
\hline Lama guanicoe & 416 & 285 & 9 \\
\hline Ovis aries & 10 & 8 & 2 \\
\hline Pseudalopex culpaeus & 8 & 2 & 1 \\
\hline Bos turus & 6 & 5 & 1 \\
\hline Ctenomys magellanicus & 2 & 2 & 1 \\
\hline Mam. indeterminado & 53 & 11 & 2 \\
\hline
\end{tabular}

Por otro lado, se realizó un análisis de densidad ósea utilizando los índices propuestos por Stahl (1999), el que indicó que la representación de unidades esqueletarias no estaría afectada significativamente por la densidad de los huesos $(r=0,159$ $p=0,392 n=44)$. De esta forma, encontramos muy bien representadas unidades tanto de alta densidad ósea, como la escápula, pelvis y calcáneo, como unidades de baja densidad, por ejemplo axis, húmero y fémur. La representación de partes esqueletarias, tanto para los individuos adultos como juveniles, muestra una alta presencia de unidades como el cráneo, axis, pelvis, escápula, húmero, radio-ulna, fémur y calcáneo. La baja presencia de falanges, junto a la total ausencia de sesamoideos, indica que

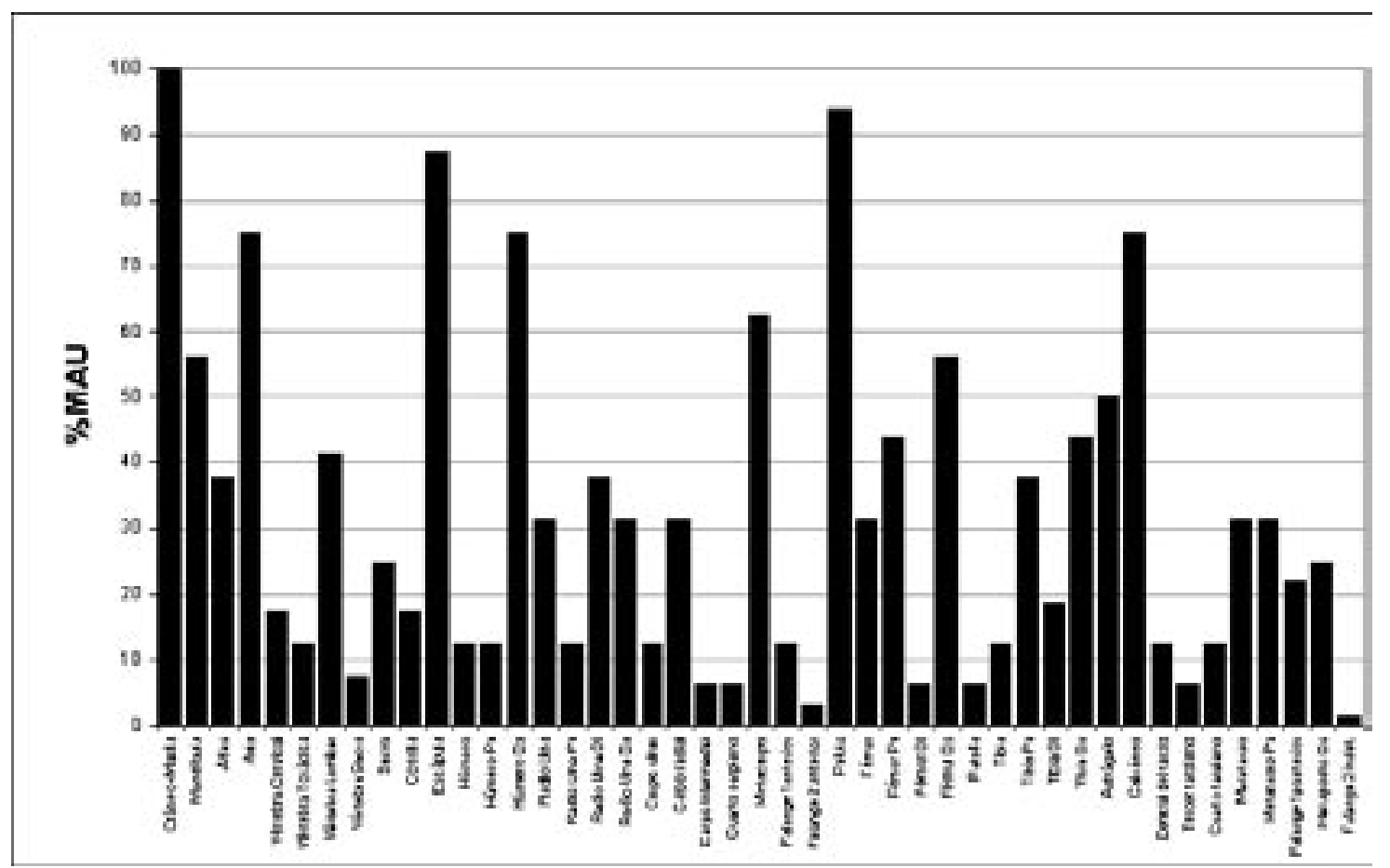

Fig. 8. Gráfico con el \%MAU de los huesos de guanaco analizados. 
las extremidades inferiores seguramente ingresaron desarticuladas al yacimiento. Otras unidades poco representadas son las costillas, los carpianos y tarsianos, y el segmento cervical y torácico (Fig. 8).

También se realizó un análisis de utilidad económica utilizando los índices propuestos por Borrero (1990) y De Nigris y Mengoni (2004). Los resultados indicaron que no existiría una correlación entre tales índices y la frecuencia de partes esqueletarias observada en el yacimiento $(r=0,240 p=0,127$ $n=42$ y $r=0,030 p=0,847 n=44$, respectivamente). A partir de esto, y de la presencia de un amplio espectro etario para los guanacos, podría proponerse una ausencia de selectividad, tanto del animal como de las presas que éste proporciona.

En cuanto a las modificaciones culturales, éstas son bastante abundantes, encontrándose presentes en un 31\% de los especimenes asignados a Lama guanicoe. Las huellas de termoalteración
Tabla 2. Frecuencia de huellas de corte por unidad anatómica en huesos de guanaco.

\begin{tabular}{|c|c|c|c|}
\hline $\begin{array}{c}\text { Unidad } \\
\text { Anatómica }\end{array}$ & MNE & $\begin{array}{c}\text { MNE con } \\
\text { huellas de corte }\end{array}$ & $\begin{array}{c}\text { \%MNE con } \\
\text { huellas de corte }\end{array}$ \\
\hline Mandíbula & 9 & 3 & 33,3 \\
\hline Axis & 6 & 1 & 16,6 \\
\hline Vértebra cervical & 8 & 4 & 50 \\
\hline Vértebra torácica & 12 & 3 & 25 \\
\hline Vértebra lumbar & 23 & 9 & 39,1 \\
\hline Sacro & 3 & 1 & 33,3 \\
\hline Costillas & 33 & 15 & 45,5 \\
\hline Escápula & 14 & 4 & 28,6 \\
\hline Húmero & 14 & 7 & 50 \\
\hline Radio-ulna & 11 & 4 & 36,3 \\
\hline Metacarpo & 10 & 3 & 30 \\
\hline Pelvis & 15 & 4 & 26,7 \\
\hline Fémur & 14 & 4 & 28,6 \\
\hline Tibia & 9 & 3 & 33,3 \\
\hline Metatarso & 10 & 4 & 40 \\
\hline Metapodio & 8 & 1 & 12,5 \\
\hline
\end{tabular}
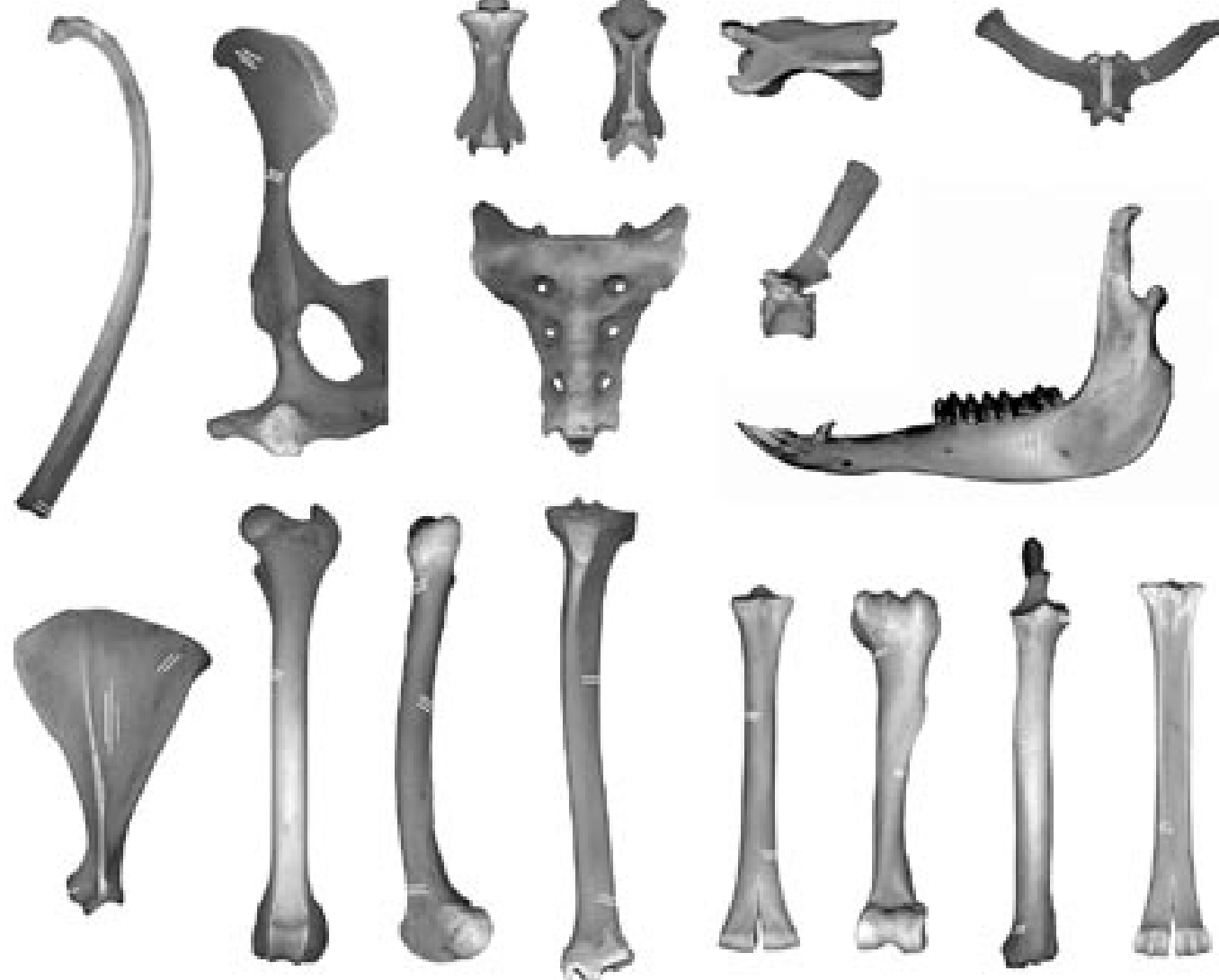

Fig. 9. Representación de algunos de los huesos con huellas de corte y su ubicación (imágenes adaptadas de Sierpe et al. 2006). 
se encuentran totalmente ausentes, sin embargo la observación de este tipo de marcas se vio dificultada por la coloración oscura que presentan los huesos. Por su parte, las huellas de corte y de fractura son abundantes en el conjunto, ubicándose en la mayor parte de las unidades anatómicas. Las huellas de corte se relacionan principalmente con el destazamiento de unidades de alto y mediano rendimiento (p.ej. segmento vertebral, costillas, escápula, húmero, radio-ulna, pelvis, fémur, tibia), y con el descarne de las mismas (Tabla 2). Este tipo de huellas se encuentra tanto en los individuos adultos como en juveniles y neonatos, lo que evidencia que todos los rangos étareos estarían siendo aprovechados (Fig. 9).

Las huellas de fractura se encuentran en la mayor parte de los huesos de las extremidades anteriores y posteriores, seguramente relacionándose a la extracción de médula ósea. Además, la mayoría de las vértebras lumbares registradas presentaron fractura por percusión de los procesos transversos, los que se encuentran casi ausentes en el conjunto, quizás debido al modo de trozamiento de la unidad (Fig. 10 y 11).

Por último, se registraron varios especímenes que presentan patologías: un carpo radial fusionado a un carpo intermedio de juvenil; un tercer tarsiano fusionado a un cuarto tarsiano (Fig. 12) de un individuo juvenil; dos cráneos de adulto que no presentan el alveolo para el canino; un cráneo juvenil que posee un alveolo más entre el canino y el premolar; y una mandíbula que sólo posee el segundo y tercer molar (individuo adulto), y un diente pequeño junto al segundo molar, sin indicios de los alvéolos para los demás dientes. Por lo tanto, el MNI total sería de 3 individuos con patologías, un juvenil y dos adultos, entre los cuales uno es macho.

\section{EL MATERIAL LÍTICO}

Los artefactos líticos recuperados en las excavaciones son en total 36 piezas, de las cuales 30 corresponden a material de talla lítica y los otros 6 son artefactos manufacturados por trituramiento o definidos por sus huellas de uso (e.g. percutores). La categoría de instrumento más importante es la raedera, predominando aquéllas de bordes denticulados, y luego le siguen las bolas (Tabla 3, Fig. 13, 14 y 15). La distribución espacial de los hallazgos

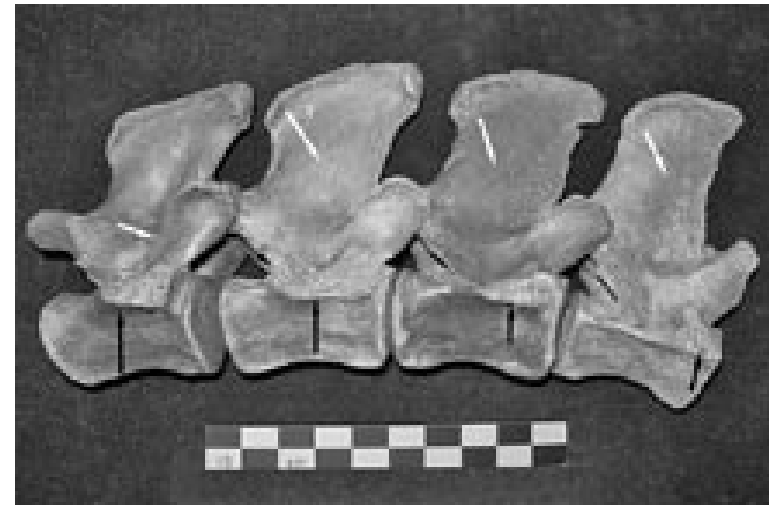

Fig. 10. Vértebras lumbares con fracturas (flechas negras) y huellas de corte (flechas blancas).

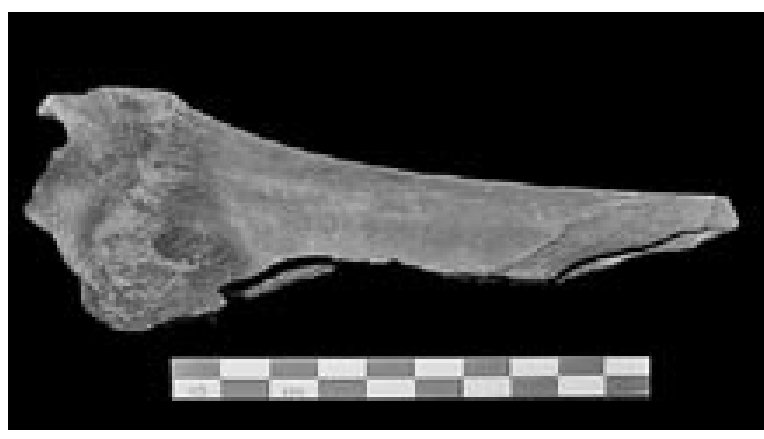

Fig. 11. Tibia de guanaco con fracturas antrópicas.

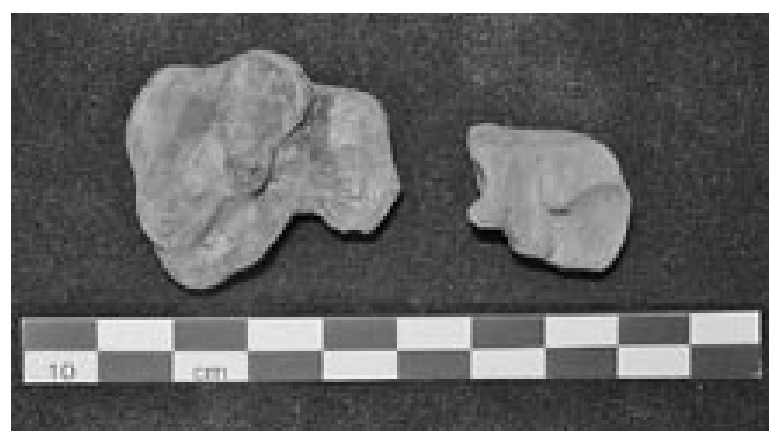

Fig. 12. Huesos de guanaco con patologías.

líticos es notable, en tanto en las unidades $1 \mathrm{~A}$ y $1 \mathrm{~B}$ (excavación 2006) se concentran todas las raederas recuperadas, y se presenta una baja densidad de materiales. En conjunto con la unidad $1 C$, reúnen solamente el 33\% del material lítico. El resto de las categorías, principalmente lascas y núcleos y/o split, se distribuyen en la unidad 1C (2006) y en el pozo, realizado en 1999. Aunque la mayor parte de los artefactos líticos recuperados se concentra en la unidad Pozo de 1999 (67\%). 
Tabla 3. Frecuencia de artefactos líticos por categoría.

\begin{tabular}{|l|c|c|c|c|c|}
\cline { 2 - 6 } \multicolumn{2}{c|}{} & \multicolumn{4}{c|}{ FRECUENCIA POR UNIDAD } \\
\hline CATEGORÍA & $1 \mathrm{~A}$ & $1 \mathrm{~B}$ & $1 \mathrm{C}$ & POZO & TOTAL \\
\hline raedera denticulada (retoque marginal simple) & & 1 & & & 1 \\
\hline raedera denticulada en punta (marginal doble) & 1 & & & & 1 \\
\hline raspador-raedera denticulada (retoque marginal total) & 1 & & & & 1 \\
\hline raedera (marginal simple) & 1 & 1 & & & 2 \\
\hline núcleo & & & 1 & & 1 \\
\hline núcleo split & & & & 4 & 4 \\
\hline split & & & & 1 & 1 \\
\hline split/ tajador & & & 1 & & 1 \\
\hline lasca & & & 2 & 12 & 14 \\
\hline desecho & & & 1 & 3 & 4 \\
\hline bloque fracturado & & & & 1 & 1 \\
\hline guijarro plano & & & 1 & & 1 \\
\hline bola & & & & 3 & 3 \\
\hline percutor blando? & & & 1 & & 1 \\
\hline Total general & 3 & 2 & 7 & 24 & 36 \\
\hline
\end{tabular}

El estado de conservación de los materiales es bueno, con un predominio de piezas enteras y fracturadas. Aunque en los instrumentos cortantes -las raederas- predominan las piezas fracturadas (1 entera, 3 fracturadas y 1 fragmento) y, al contrario, las 3 bolas están enteras. Los núcleos representados y los casos de split ${ }^{8}$ están enteros, y la mayoría de las lascas y desechos de talla se encuentran fracturados/fragmentados (33\% enteros, 22\% fracturados y $45 \%$ de fragmentos ${ }^{9}$ ).

Los desechos líticos, representados principalmente por lascas internas (angulares y lisas), sugieren el desarrollo de las etapas finales de una o varias cadenas operatorias de manufactura de soportes -desbaste- de lascas en el yacimiento. Los elementos de análisis son escasos, al igual que la cantidad de piezas, por lo que es muy difícil lograr comprender mejor los métodos de desbaste implementados y el detalle de las cadenas operatorias. No obstante, se pueden esbozar las siguientes observaciones:

- Dos lascas internas fracturadas, presentan una preocupada preparación del talón para percusión dura y blanda respectivamente. Junto con el soporte de una raedera pequeña (Fig. 14, inferior), son los únicos productos de desbaste con talón fa-

8 Por split se entiende un método de fractura de un bloque o masa central por percusión dura sobre yunque y que es poco controlada (Morello 2005).

9 El criterio utilizado para diferenciar entre fragmentos y lascas fracturadas es la ausencia de talón en los primeros. cetado. La morfología de las piezas es de tendencia alargada y espesor relativamente uniforme en el eje longitudinal. Los fragmentos de negativos de la cara dorsal de estas 3 piezas son paralelos a la superficie de desbaste (Inizian et al. 1995). Las dos lascas internas fracturadas pueden considerarse como muy buenos soportes traídos al sitio y descartados al fracturarse o lascas desbastadas y fracturadas in situ pero descartadas por este accidente. En 4 de

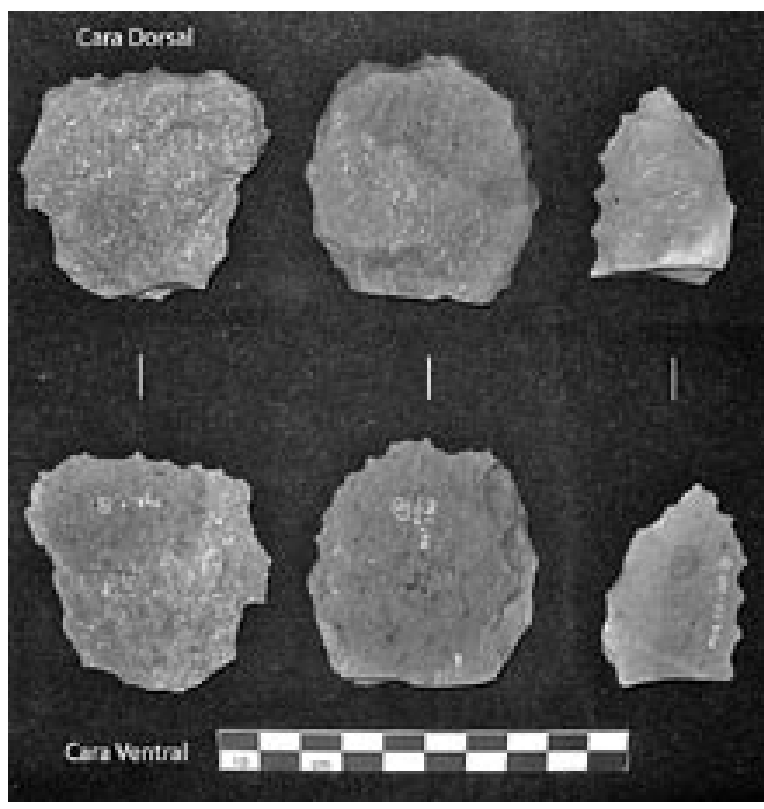

Fig. 13. Vista dorsal (retocado) y ventral de las tres raederas denticuladas registradas en Myren 2. La del medio fue clasificada como raspador-raedera. 


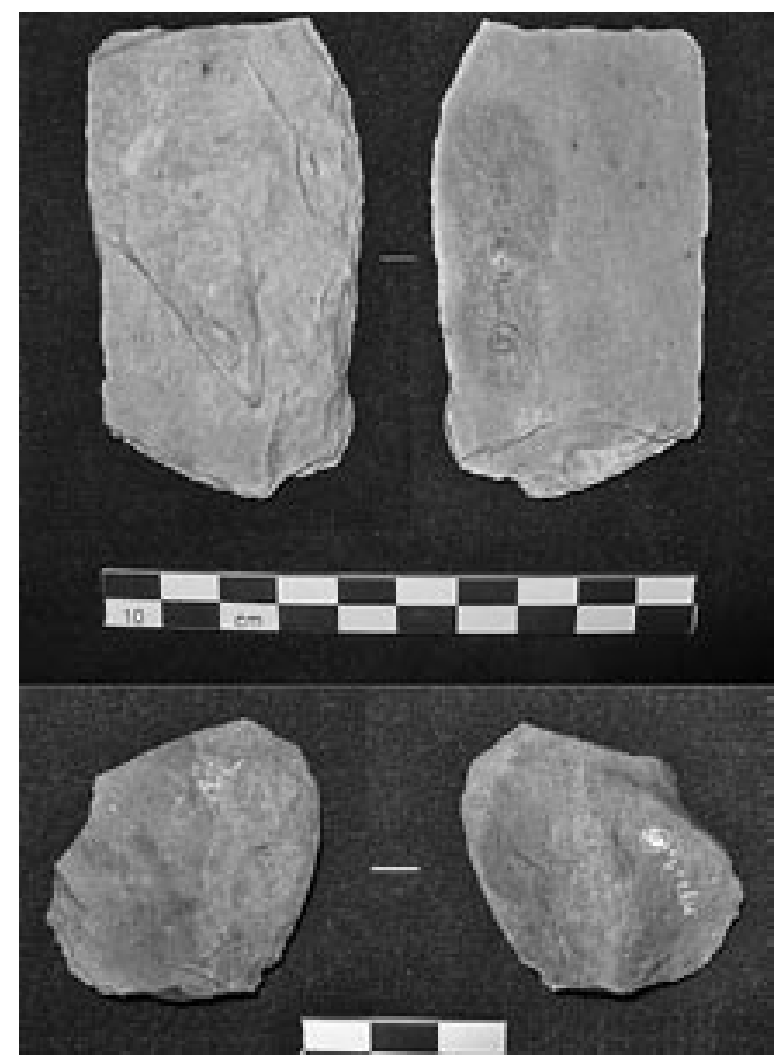

Fig. 14. Vista dorsal y ventral de las otras dos raederas recolectadas en el sitio.

las 5 raederas ${ }^{10}$, incluyendo las denticuladas que son predominantes, las lascas de soporte presentan esta morfología uniforme y negativos paralelos a la superficie de desbaste. Es decir, hay una producción predeterminada y planificada (Fig. 13 y 14).

- Otro caso interesante es una lasca de reavivado de borde de instrumento con retoque marginal, compatible con una raedera (ni la materia prima ni la pieza coinciden con los instrumentos registrados en el sitio). La técnica de extracción fue la percusión blanda. La lasca es bastante invasiva, extrayendo toda una sección del borde retocado y proyectándose bastante hacia el interior de la pieza original,

10 La que se excluye esta manufacturada sobre una roca silícea sedimentaria que se meteoriza formando laminillas como las lajas y el esquisto, el soporte de dicha raedera parece una lasca del tipo en tajadas sobre yunque (Morello 2005) pero podría tratarse de un soporte natural generado por una fractura no antrópica (Fig. 14, superior). Como la pieza no presente talón, es muy difícil asignarle una agencia clara al soporte. No obstante su carácter burdo, el retoque es antrópico.
Tabla 4 Frecuencia de desechos de talla por tipo.

\begin{tabular}{|l|c|}
\hline \multicolumn{1}{|c|}{ TIPO DESECHO } & TOTAL GENERAL \\
\hline secundaria, lasca & 3 \\
\hline dorso natural, lasca & 3 \\
\hline interna, lasca & 1 \\
\hline angular, lasca & 4 \\
\hline lisa, lasca & 1 \\
\hline reavivado, lasca de & 1 \\
\hline indet., desecho & 5 \\
\hline Total general & 18 \\
\hline
\end{tabular}

siguiendo nervaduras similares. De esta manera se renovó - al menos en esta parte de manera exitosa- el ángulo del borde del instrumento, que presentaba una sección plano-convexa con un ángulo cercano a $90^{\circ}$ y una acumulación de bisagras.

- Hay dos lascas angulares enteras de talón liso con un ángulo de talón muy abierto (135-140), cortas y espesas, que están reflejando algún tipo de preparación de desbaste organizado con relación a un plano de percusión liso y plano - valga la redundancia - y en ángulos secantes. Una de estas lascas de ángulo secante tiene unos retoques marginales aislados conformando un borde tipo raspador. Los fragmentos de negativos de ambas lascas son multidireccionales y con tendencia a converger hacia la parte distal. Estas lascas deben insertarse de una manera no determinable, por el momento, en algún método de formatización o manutención de núcleos.

- Un segundo caso de retoques marginales aislados en un borde de una lasca formando un pequeño cuchillo podría estar reflejando el reavivado de filos naturales. Este aspecto deberá evaluarse en el futuro analizando con microscopía otras lascas, con y sin retoque, y la presencia de huellas de uso.

Con relación a las bolas registradas, las tres piezas se encuentran completas y presentan una morfología esferoidal, dos de estas con surco completo en el eje perpendicular al de rotación de la pieza y una paralelo (Fig. 15). Dos de estas piezas fueron elaboradas sobre una materia prima con alto contenido en óxido de hierro y una tercera sobre gabro. En las 3 piezas la elaboración del surco es prolija, coincidiendo en surcos de sección oblicua a recta. El ancho de surco es muy angosto, máximo 4 mm y el acabado del surco no depende de la materia prima ya que el gabro y la otra materia prima ferrosa utilizada presentan granulometría y consistencias 


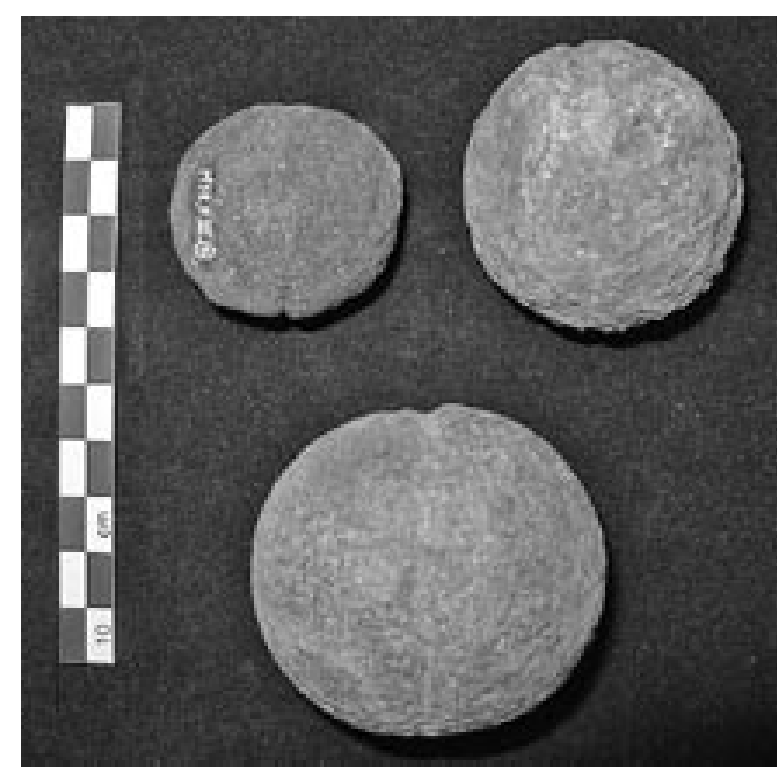

Fig. 15. Bolas de boleadora con surco.

diferentes ${ }^{11}$. En este sentido es sugerente el parecido con algunas piezas de Marazzi 1, con fechados asignados a este periodo; esto se manifiesta en el uso de materias primas en especial la roca con alto contenido de óxido de fierro y también en la elaboración y morfología del surco. Esto, por ejemplo a diferencia de lo observado en las bolas del sitio La Arcillosa 2, también temporalmente asignables a cazadores terrestres del Holoceno medio (Salemme et al 2007), cuyos surcos son más anchos y de sección más abierta.

11 La primera bola presenta la superficie formatizada por pulido, el surco se ubica en el eje menor de la pieza, el que presenta una sección oblicua a recta elaborado probablemente por raspado e incisiones, la profundidad del surco es mayor al de las demás piezas, al igual que el peso especifico (peso: 226 gr., largo: 55,4 mm, ancho: 50,4 mm, espesor: $50 \mathrm{~mm}$ ). La otra bola de igual materia prima que la anterior, presenta un peso de $141 \mathrm{gr}$ (largo: $48 \mathrm{~mm}$, ancho: $46 \mathrm{~mm}$, espesor: $41 \mathrm{~mm}$ ) y la superficie se encuentra menos formatizada que la anterior lograda por piqueteado y extracciones. El surco se ubica en el eje mayor ( paralelo al eje de rotación), aunque no significativamente superior al otro diámetro de la pieza, la elaboración del surco también presenta sección oblicua a recta bien elaborada (№8 dibujo de planta Fig. 7). La tercera bola es la más pequeña en tamaño y peso (peso: 75 grs, largo: $38 \mathrm{~mm}$, ancho: 35,6 mm, espesor: 30,5 $\mathrm{mm})$, se encuentra elaborada sobre gabro. La superficie se encuentra piqueteada y alisada (abrasión). El surco se ubica en el eje menor de la pieza, también presenta una sección muy recta lograda por una incisión profunda.
Por el momento, se sugiere la posibilidad de que las tres bolas corresponden a distintas boleadoras, por sus dimensiones y pesos disímiles, pudiendo quedar abandonadas al arrojarlas en el evento de caza de la presa, resultando pérdidas en el lugar.

Con relación a las bolas registradas, las tres piezas se encuentran completas y presentan una morfología esferoidal con surco completo en el eje perpendicular al de rotación de la pieza. Una de estas piezas es de una materia prima con alto contenido en óxido de hierro, presenta la superficie formatizada por pulido, el surco se ubica en el eje menor de la pieza, el que presenta una sección oblicua a recta elaborado probablemente por raspado e incisiones, la profundidad del surco es mayor al de las demás piezas, al igual que el peso especifico (226 grs.).

La otra bola de igual materia prima que la anterior, presenta un peso de 141 grs y la superficie se encuentra menos formatizada que la anterior lograda por piqueteado y extracciones. El surco se ubica en el eje mayor, aunque no significativamente superior al otro diámetro de la pieza, la elaboración del surco también presenta sección oblicua a recta bien elaborada (№8 dibujo de planta fig.).

La tercera bola es la más pequeña en tamaño y peso (75 grs.), se encuentra elaborada sobre gabro. La superficie se encuentra piqueteada y alisada (abrasión). El surco se ubica en el eje menor de la pieza, también presenta una sección muy recta lograda por una incisión profunda.

Cabe destacar en las 3 piezas la elaboración prolija del surco coincidiendo en surcos de sección oblicua a recta. El ancho de surco también es muy angosto, tendiendo como máximo $4 \mathrm{~mm}$. También destaca que el acabado del surco no depende de la materia prima ya que el gabro y la otra materia prima ferrosa utilizada presentan granulometría y consistencias diferentes. En este sentido es sugerente el parecido con algunas piezas de Marazzi 1 con fechados asignados a este periodo; esto se manifiesta en el uso de materias primas en especial la roca con alto contenido de óxido de fierro y también en elaboración del surco de sección muy oblicua a recta y de un ancho entre 2 a $4 \mathrm{~mm}$ preparado por una incisión o un raspado fino. La profundidad del surco también es destacable en las piezas de ambos sitios. A diferencia de lo observado en las bolas de el sitio La Arcillosa 2 también temporalmente asignables a cazadores terrestres del Holoceno medio 


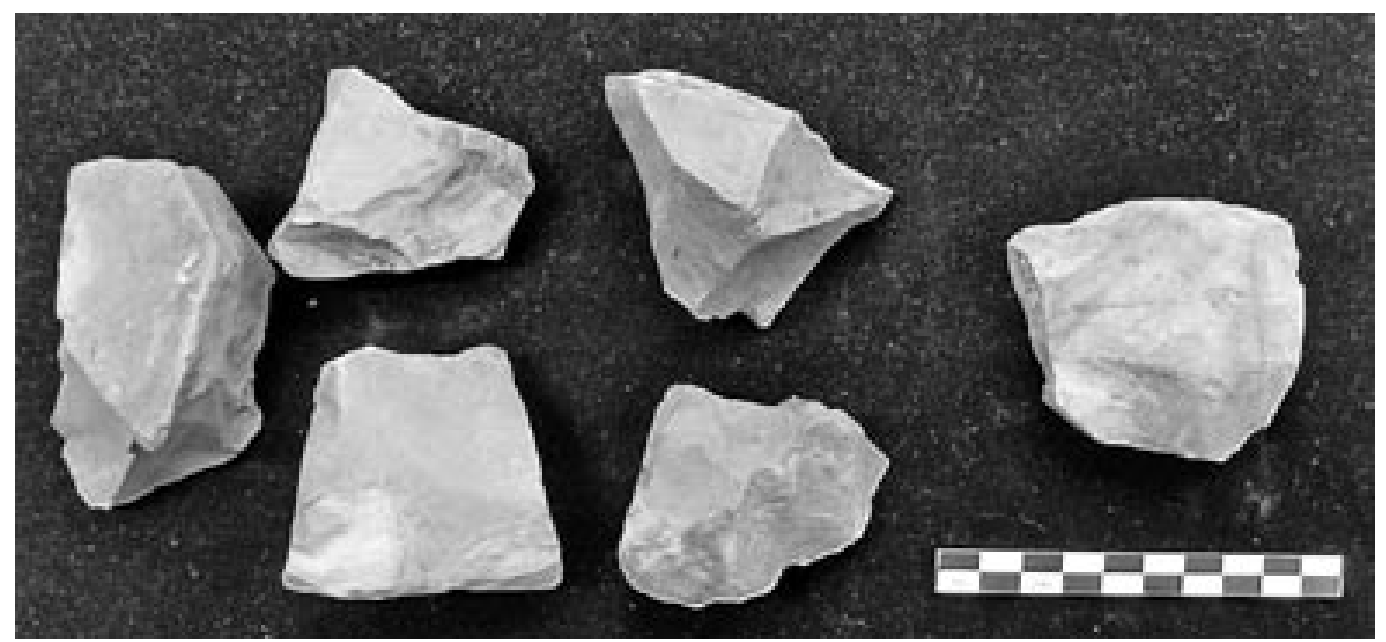

Fig. 16. Conjunto de rocas sedimentarias registradas en Myren 2: 4 núcleos-split, 1 fragmento de bloque fracturado y una lasca, a la derecha. Todos estos artefactos pertenecen al mismo nódulo de materia prima.

(Salemme et al. 2007), los surcos son más anchos y de sección más abierta.

Por el momento se suguiere la posibilidad que las tres bolas corresponden a distintas boleadoras, por sus dimensiones y pesos disímiles, pudiendo quedar abandonadas al arrojarlas en el evento de caza de la presa, quedando perdidas en el lugar.

La riqueza de materias primas es notable en el sitio, registrándose 26 rocas distintas entre 36 piezas. Considerando solamente los restos de talla, hay 23 nódulos de materias primas distintas representadas, (3 sedimentarias, 1 roca silícea y 19 otras indeterminadas).

A partir de las materias primas representadas al menos por dos artefactos, que es el caso de solamente 5 rocas, se ha podido registrar otras observaciones técnicas de interés y verificar la coherencia espacial de eventos puntuales de depositación:

- Un fragmento muy pequeño del raspadorraedera denticulado fue encontrado en la cuadrícula 1C (Cuadro 1A). No remontan, pero son de la misma materia prima, morfología y espesor.

- En la cuadrícula $1 C$ se recolectaros 3 artefactos de una roca indeterminada de calidad regular. Se trata de un núcleo desbastado bipolarmente apoyado sobre yunque, que ha sido remontado con un fragmento de lasca secundaria. Además hay un tercer fragmento de desecho indeterminado, sobre el mismo nódulo de materia prima. El núcleo presenta una potencial plataforma de percusión lisa pero no fue usada, en el estado de abandono de núcleo no se observan negativos asociados.

- Luego, hay un guijarro astillado por percusión sobre yunque tipo split, bastante grande, del que potencialmente pudieron usarse sus filos naturales, y un fragmento de desecho indeterminado del mismo guijarro. Ambos provienen de la unidad Pozo.

- Dos lascas de una materia prima semejante a la vulcanita, y de buena calidad, fueron recuperadas en esta misma unidad Pozo de 1999. Se trata de una lasca de dorso natural, entera, de talón liso y extraída por percusión sobre yunque. La otra, una lasca secundaria entera (70\% corteza) y con una talón puntiforme (percusión dura). El análisis del remontaje permite reconstituir el desbaste de un guijarro, estando representada la apertura de plataformas de percusión, alternándose dos técnicas.

- Por último, hay 6 piezas de un mismo nódulo de roca sedimentaria de calidad regular, 4 núcleos de split, 1 fragmento de bloque y 1 lasca angular (Fig. 16). La percusión sobre yunque, poco controlada, es evidente en todos los casos, excepto la lasca que probablemente fue extraída con percusión dura. Los núcleos de split registrados presentan formas poliédricas, con uno o dos ejes de percusión bipolar, el tipo de fracturación genera aristas en punta, a veces con puntos de percusión asociados. Como aspecto adicional, para evaluar en el futuro, la lasca angular presenta un borde distal, buen ángulo y forma para su uso como filo vivo. 
En resumen, el conjunto lítico recuperado en Myren 2 es desconcertante, por la riqueza del conjunto. Están representadas dos estrategias tecnológicas (sensu Nelson 1991): Una estrategia de conservación asociada a los instrumentos abandonados por accidente -fracturas que suponemos accidentes por uso (raederas)-, lascas internas de morfología uniforme y talón preparado (también fracturadas) y una lasca de reavivado del filo de un borde retocado compatible con una raedera. Todas estas piezas incluyen artefactos aportados al sitio de manera preparada y planificada, y reflejan las últimas etapas de manufactura y manutención de soportes $e$ instrumentos $-y$ suponemos su utilización. Estas piezas son todas de materias primas distintas y de buena calidad, en general.

Segundo, y conformando una concentración distinta en el espacio, se registran núcleos, lascas $y$ otros artefactos tallados en parte en el sitio, con varias piezas de una misma materia prima, aspecto demostrado por algunos remontajes y por la identificación de nódulos individuales (remontajes mentales). Son en general artefactos de manufactura burda, predominando la percusión sobre yunque del tipo split $-y$ por lo tanto poco controlada $-y$ materias primas de regular calidad. Este conjunto refleja una estrategia expeditiva cuyos productos objetivo están aún difusos.

\section{DISCUSIÓN Y CONCLUSIONES}

La extraña presencia de gran cantidad de restos óseos y algunos materiales líticos en un pequeño espacio, y en un ambiente sedimentario (tipo turbal) tan especial igualmente, motiva a elaborar varias explicaciones de su depositación. Los análisis faunísticos y líticos realizados permiten sugerir algunas alternativas:

¿Un escondrijo de materiales y alimentos?

Podría pensarse que los restos fueron arrojados a la vertiente natural pre-existente o insertados en las paredes de turba de ésta. Pero los restos líticos no avalan esta alternativa. Si fuera un escondrijo este definiría piezas valiosas de algún modo. Pero el análisis lítico no parece corroborar esta alternativa ya que una parte de los instrumentos, las raederas, se hallaron fracturados. Sabemos por Martin Gusinde (1982) que los Selk'nam de la misma Tierra del Fuego guardaban carne en turberas, para conservar algunos trozos, pero ello es difícil de evaluar en este caso.

\section{¿Un evento de caza comunal?}

Resulta extraño que aparezcan huellas de impacto y corte sobre algunos huesos mientras otros parecen haber sido dejados intactos, sin intentar siquiera la extracción de la médula, o los sesos de cráneos enteros. Puede tratarse de un episodio de abundancia momentánea, de una caza colectiva de un grupo familiar de guanacos (cfr. Borrero 1990), en verano, tal como lo sugeriría la abundancia de juveniles en la muestra, incluso de neonatos. Varias clases de edad se hallan representadas, y ambos sexos. La misma vertiente pudo ser la ocasión de la caza o la trampa de la misma. Sin embargo, la presencia de dos guanacos machos adultos en el conjunto le resta un tanto de credibilidad, dado que los grupos familiares están conformados por un macho dominante, hembras de distintas edades y machos juveniles de hasta 1 año. Si superponemos los conteos de NMI de 1999 con los del 2006'2, habrían entre un mínimo de 9 y 11 animales representados, y más de la mitad juveniles.

¿Carroñeo de animales que morían empantanados de tanto en tanto?

Esto sería avalado por el hecho de haber huesos procesados y otros no, los animales habrían quedado sumergidos de un lado, mientras el otro se encontraban a la intemperie. Se trataría de animales enteros, pero no enteramente aprovechables. Hay una ligera desproporción de calcáneos derechos e izquierdos en el sitio, por ejemplo. Por otro lado, la arcilla blanda empantana animales en la actualidad, al igual que algunos pozos o vertientes actúan como trampas de ovejas y vacunos y por lo mismo son cercados por los propietarios de los predios. Además, aparecen al menos 3 animales con patologías, aunque

12 En la recuperación de materiales óseos del año 1999, provenientes de los escombros del pozo de agua, se realizó un análisis in situ de los restos peor conservados, no siendo posible su recolección. Entonces fue que se identificaron 11 guanacos a partir de sus fémures. 
no sabemos la ingerencia de estas enfermedades en la causa de muerte de los individuos. Esta alternativa es más plausible hacia el comienzo de la formación de la turba, al parecer es la arcilla blanda bajo ella, la que aprisiona.

¿Un sitio con un particular componente lítico?

Las categorías de materiales líticos abandonados, la variedad de materias primas, la presencia, por otro lado, dentro de los instrumentos líticos, de tres denticulados y tres bolas con surco, otorga a este sitio un particular status al compararlo con otros sitios de la Tierra del Fuego. Por un lado, en escasos artefactos, hay dos estrategias tecnológicas bastante diferentes representadas. Se registra cierta organización espacial en los hallazgos, concentrándose las raederas en dos unidades, las bolas en otras y los restos de núcleos y desechos, también. Efectivamente, la presencia de raederas denticuladas es un elemento extraño en la isla, siendo un procedimiento tecnológico cuyos contextos de referencia mejor conocido en la actualidad están ejemplificados en las puntas lanceoladas de Ponsonby y Lancha Packewaia (Legoupil 2003, Orquera et al. 1977). También en Lancha Packewaia se describen instrumentos sobre lasca denticulados, dos en el Componente Reciente y uno en el Componente Antiguo. Otros casos de denticulados se han registrado como instrumentos tipológicamente aislados en industrias casapedrenses (Crivelli 1980) y en hallazgos superficiales en Ultima Esperanza (Río Don Guillermo). Un caso particular es la presencia de denticulados como un elemento diagnóstico de las industrias riogalleguenses (Sanguinetti de Bórmida 1972). En las cercanías del casco de la estancia se encuentra otro sitio, Myren 1 , a cielo abierto y ubicado en un paraje más seco, con una data de ca. 900 años AP (Massone et al. 1999). En este sitio se encontraron puntas de proyectil y abundantes huesos de guanaco, entre ellos varios machacadores óseos (Hajduk y Lezcano 2005). Los machacadores no aparecen en Myren 2 , aspecto que es tan llamativo como la presencia de raederas denticuladas. El registro de estos machacadores óseos o corte perimetral sobre epífisis de huesos largos de guanaco es muy común en el registro del centro y norte de Tierra del Fuego. Es posible cuestionarse si la técnica no había aparecido aún hacia los 4.000 años AP o si la función del sitio no los hacía necesarios. En conjunto, los artefactos líticos registrados en Myren 2 son desconcertantes tanto desde del punto de vista funcional como por ser distinto a los complejos culturales conocidos para tiempos tempranos y tardíos, tanto entre los grupos terrestres (e.g. periodificación de Bird 1993) como entre los canoeros (e.g. Legoupil y Fontugne 1997, Orquera y Piana 1999).

En definitiva, el sitio es extraordinario desde el punto de vista de la abundancia de restos y su preservación, y la variedad de hipótesis que ha permitido plantear. A la datación original se suman ahora dos más que son bastante coincidentes, también sobre hueso de guanaco, todas entorno a los 4.000 años AP, y los sondeos realizados en los años 1999 y 2006 sustentan que se trata de un contexto concentrado en un reducido espacio, en torno al turbal.

La presencia de huesos en turbales o humedales en Tierra del Fuego fue destacada tempranamente por Bonarelli (et al. 1917), sin embargo, podría haberse tratado de restos paleontológicos. La primera evidencia de un sitio arqueológico en la proximidad de un turbal fue dada a conocer por José Emperaire (1988): Ponsonby, en isla Riesco. El ambiente, en todos estos casos, era más que propicio para la conservación de los restos óseos (Legoupil 2003). Este tipo de sitios ha sido escasamente tratado en la literatura arqueológica de Fuego-Patagonia (e.g. Proyecto Fondecyt 1070709), esta característica sumada a este feliz hallazgo, podría instar a otros colegas a ensayar la búsqueda de sitios como Myren 2 y aprovechar su buena conservación para futuros estudios.

\section{AGRADECIMIENTOS}

Un agradecimiento especial merece Harold y Bernardo Krussel, dueños de la Estancia Myren, los que no solamente informaron del hallazgo sino que siempre apoyaron nuestras iniciativas de investigación. También debemos reconocer el apoyo de Mauricio Massone, quien dirigió el proyecto en el que se descubrió e iniciaron los trabajos en Myren 2 , y a Roxana Seguel que colaboró en las labores de terreno en 1999.

Igualmente, agradecemos a Pedro Cárdenas y Gabriel Bahamonde por su colaboración en el trabajo de terreno en el año 2006. 


\section{BIBLIOGRAFÍA}

BIRD, J. 1993. Viajes y Arqueología en Chile Austral. Ediciones de la Universidad de Magallanes., Punta Arenas, Chile.

BORRERO, L.A. 1990. Fuego-patagonian bone assemblages and the problem of communal guanaco hunting. En: Hunters of the Recent Past. L.B. Davis y B.O.K. Reeves (eds.), pp. 373-399. London: Unwin Hyman.

BONARELLI, G.; E. HERMITTE y J. KEIDEL. 1917. Tierra del Fuego y sus turberas. Ministerio de Agricultura, Buenos Aires.

CRIVELLI, E. 1980. La industria Casapedrense (Colección Menghin). Runa XIII(1-2):35-57.

DE NIGRIS, M.E. y G.L. MENGONI GOÑALONS. 2004. El guanaco como fuente de carne y grasas en Patagonia. En: Contra viento y marea. Arqueología de Patagonia, pp. 469-476, T. Civalero, P. Fernández y A. G. Guráieb (compiladores). INAPL y Sociedad Argentina de Antropología, Buenos Aires.

EMPERAIRE, J. 1988. Paisajes y hombres prehistóricos de la Patagonia. Anales del Instituto de la Patagonia, Serie Ciencias Sociales 18:79-94.

GUSINDE, M. 1982 [1931]. Los Indios de la Tierra del Fuego. Los Selk'nam Vol. I, Buenos Aires.

HADJUK, A. y M. LEZCANO. 2005. Un nuevo viejo integrante del elenco de instrumentos óseos de Patagonia: los machacadores óseos. Magallania 33 (1): 63-80.

INIZAN, M.-L., M. REDURON, H. ROCHE y J. TIXIER. 1995. Technologie de la Pierre Taillée 4. CREP (Cercle de Recherches et d'Études Préhistoriques, CNRS), Meudon.

LEGOUPIL, D. 2003. Cazadores-Recolectores de Ponsonby (Patagonia austral) y su paleoambiente desde VI al III milenio A.C. Magallania Vol. 31, número especial, Punta Arenas. Ediciones de la Universidad de Magallanes.

LEGOUPIL, D. y R. FONTUGNE. 1997. El Poblamiento marítimo en los archipiélagos de Patagonia: núcleos antiguos y dispersión reciente. Anales del Instituto de la Patagonia, Serie Ciencias Humanas 25:75-87.
MASSONE, M.; A. PRIETO; D. JACKSON; X. PRIETO; G. ROJAS; R. SEGUEL y L. BORRERO. 1999. Hombre Temprano y Paleoambiente en Tierra del Fuego. Informe Final, Proyecto FONDECYT 1960027.

MORELLO, F. 2005. Tecnología y métodos para el desbaste de lascas en el norte de Tierra del Fuego: los núcleos del sitio Cabo San Vicente. Magallania 33(2):29-56.

MORELLO, F., M. SAN ROMÁN y A. PRIETO. 2002. Puntas de proyectil lanceoladas en Patagonia meridional y Tierra del Fuego. Anales del Instituto de la Patagonia, Serie Ciencias Humanas 30:155-166.

NELSON, M. 1991. The study of technological organization. En: Archaeological Method and Theory, edited by M. Schiffer, pp. 57-100. University of Arizona Press, Tucson.

ORQUERA, L. A., A. E. SALA, E. PIANA and A. H. TAPIA. 1977. Lancha Packewaia. Arqueología de los Canales Fueguinos. Colección Temas de Arqueología 1. Huemúl editores.

RAEDEKE, K. 1979. El guanaco de Magallanes, Chile. Distribución y biología. Corporación Nacional Forestal (CONAF), Santiago.

SANGUINETTI DE BÓRMIDA, A.C. 1972. Algunas consideraciones acerca de recientes investigaciones sobre la industria riogalleguense. Anales de Arqueología y Etnología XXVI:43-46.

SIERPE, V.; A. PRIETO, R. CÁRDENAS y G. BAHAMONDE. 2006. Anatomía Ósea del Guanaco (Lama guanicoe). Poster presentado en el Primer Congreso de Estudiantes de Biología de Chile AEBECH, Valdivia 2006, y Segundo Congreso de Iniciación Científica, Universidad de Magallanes, Noviembre 2006.

STAHL, P. 1999. Structural density of domesticated South American camelid skeletal elements and the archaeological investigation of prehistoric Andean ch'arki. Journal of Archaeological Science 26:1347-1368. 
